\title{
COMUNICAÇÃO INTERNA E GESTÃO DE PESSOAS: DESAFIOS E APROXIMAÇÕES POSSÍVEIS PARA AS RELAÇÕES PÚBLICAS
}

CHARLENE DALCOL

UNIVERSIDADE FEDERAL DE SANTA MARIA SANTA MARIA, RIO GRANDE DO SUL, BRASIL CHARLENEDALCOL@GMAIL.COM

CAROLINA GRAZIADEI UNIVERSIDADE CATÓLICA DE PELOTAS PELOTAS, RIO GRANDE DO SUL, BRASIL CAROLINAGRAZIADEI@HOTMAIL.COM

FABRISE MÜLLER UNIVERSIDADE FEDERAL DE SANTA MARIA SANTA MARIA, RIO GRANDE DO SUL, BRASIL FABRISE.SMA@TERRA.COM 


\section{COMUNICAÇÃO INTERNA E GESTÃO DE PESSOAS: DESAFIOS E APROXIMAÇÕES POSSÍVEIS PARA AS RELAÇÕES PÚBLICAS}

Resumo: $O$ trabalho de Relações Públicas, como parte do processo de gestão das organizações, tem assumido novos contornos que passam pela intersecção com outros campos do conhecimento. Prova disso é a atuação de profissionais de RP junto a profissionais das áreas de gestão organizacional, como a Administração, com vistas à otimização dos processos de comunicação e relacionamento das organizações contemporâneas com os seus públicos.

Palavras-chave: Relações Públicas; Comunicação Organizacional; Comunicação Interna; Gestão de Pessoas.

\section{APONTAMENTOS INICIAIS}

As organizações mais identificadas com a realidade do mercado globalizado trabalham intensamente para adequar suas estratégias aos novos paradigmas de qualidade e competitividade. Neste contexto, a comunicação interna atua no sentido de contribuir para as organizações exercerem a sua função política, econômica, tecnológica, social e estabelecerem uma relação possível entre sujeito e organização através de formas de regulações conjuntas, que permitam uma aprendizagem recíproca. Nesse cenário, impõe-se um novo modelo de gestão das relações internas das organizações. Esse modelo preocupa-se com o homem como um ser total que executa suas capacidades de compreensão, escolha, decisão e participação, deixando de ser apenas um insumo no processo produtivo. Seus sentimentos, habilidades intelectuais, relacionais e técnicas fazem parte do cenário necessário para o desenvolvimento almejado.

Esse novo homem também é um produto da organização. Assim como a organização modifica seus processos produtivos, criando novas tecnologias, modificando seus processos sociais internos. O envolvimento necessário do trabalhador para atender às novas exigências dos processos produtivos precisa ser criado e, para tanto, faz-se necessário que a gestão de pessoas considere o homem como um ser pleno, que tem consigo sua memória, sentimentos, sua subjetividade, seu corpo e não somente alguém dotado de capacidade para acionar uma máquina ou obedecer a regulamentos e normas.

Baseado nessa ideia inicial, este estudo trata sobre os desafios e as interações possíveis entre a comunicação interna e a gestão de pessoas no âmbito 
das organizações. Reuniu-se uma série de elementos que permitem uma reflexão sobre o trabalho de Relações Públicas como mediador dessa relação potencial, considerando que ambas as atividades objetivam o sucesso das organizações e o bom relacionamento com os públicos de interesse.

Nesse contexto dinâmico, muitos outros elementos estão presentes na comunicação das organizações e ganham espaço entre os gestores de diversos setores por compreenderem a importância de um profissional capacitado, atuando como elo entre as hierarquias. O profissional de Relações Públicas além de atuar como articulador da relação entre organização e os públicos, gerencia relacionamentos e a avalia as necessidades de cada público para que se possa traçar estratégias comunicacionais. Com o foco nos desejos e nas necessidades dos indivíduos, o profissional vale-se de instrumentos e técnicas comunicacionais para mediar os relacionamentos nas organizações.

Articulando a teoria e a práxis daquelas, observa-se como a comunicação interna pode atuar junto à gestão de pessoas para o desenvolvimento de processos de comunicação integrados, participativos e com foco nas pessoas. A inspiração, neste caso, vem das proposições de Torquato (2015), Kunsch (2009), Grunig; Hunt (2003) referenciados no quadro teórico, já que os autores abordam em seus estudos a interação entre a comunicação e a gestão de pessoas. Também, segue-se o raciocínio de Gonçalves (2010, p. 46) quando afirma que a "comunicação interna de uma organização é crucial para a eficácia da gestão”.

A análise foi realizada no Sicredi Região Centro, atualmente com 95 cooperativas de crédito, 1.400 pontos de atendimento, 3,1 milhões de associados e 19,3 mil colaboradores nos 11 Estados brasileiros. Somente o Rio Grande do Sul conta com 557 unidades. A Superintendência Regional da Sicredi Região Centro, localizada na cidade de Santa Maria, atende 18 municípios da região central do Estado, com 20 unidades de atendimento e 325 colaboradores na cooperativa atualmente.

O aprofundamento dessa temática, contribui para o desenvolvimento da pesquisa científica na área de Comunicação Organizacional e Relações Públicas, por suscitar o desenvolvimento do debate sobre a importância da interação entre a comunicação interna e a gestão de pessoas, no ambiente organizacional. 


\section{A COMUNICAÇÃO E O DESAFIO DAS ORGANIZAÇÕES}

A comunicação no ambiente organizacional está além de um setor ou departamento que produz e distribui informações. Kunsch (2009) aponta que a comunicação precisa ser vista como um fenômeno inerente à natureza das organizações e que acontece em diferentes dimensões (humana, instrumental, estratégica), além de também receber influências dos contextos econômicos, sociais, políticos, culturais e tecnológicos. Na visão de Guedes (2007), o profissional que desempenha a função dentro das organizações representa o elo entre ela e os seus públicos, a que a autora atribui como sendo comunicação organizacional e ressalta que ela

\footnotetext{
[...] se efetiva através das práticas de relações públicas, responsáveis pelos fluxos relacionais, que são oportunidades de encontro, diálogo e negociação entre atores sociais. E, de forma integrada e planejada, pelas ações de jornalismo e propaganda/publicidade, que trabalham os fluxos informacionais, sejam mercadológicos ou institucionais (GUEDES, 2007, p. 65).
}

A assertiva da autora direciona a ideia de uma comunicação estratégica, onde a atuação das Relações Públicas aliada as demais áreas de jornalismo, publicidade e produção editorial otimizam os esforços de comunicação. Além de uma execução conjunta, a comunicação organizacional está vinculada ao pensamento planejado de processos e ações.

Na mesma linha de pensamento, Freitas (2009) enfatiza que os gestores precisam mudar a visão de que apenas investir dinheiro seja o principal passo para o sucesso da organização. O diálogo é uma das principais ferramentas para o desenvolvimento de bons funcionários. São eles que a representam frente ao público externo, por isso, a sua importância para compreender o papel da comunicação a fim de auxiliá-los nessa tarefa. Por essa razão, "a comunicação vem conquistando espaço entre gestores em busca de sua compreensão e real funcionalidade, pois as suas práticas estão fortemente relacionadas com as transformações ocorridas com as organizações" (CASTRO, 2014, p. 67).

Se entendermos a organização como um tecido vivo e em constante transformação, o objetivo fundamental da comunicação interna deixa de ser apenas o da informação e da difusão, para tornar-se um processo onde o diálogo é o instrumento indispensável para promover e apoiar as transformações e possibilitar ao homem organizacional passar de uma situação in- 
satisfatória para outra mais condizente com suas necessidades e aspirações enquanto ser humano e cidadão. Então, para que a comunicação interna se estabeleça, a organização deve assumir um caráter dialógico, em que o administrador fale com o empregado e não para o empregado, de modo a provocar uma simbiose de experiências sociais significativas. Deste modo, a comunicação promove a interação e a participação dos indivíduos, capacitando-os para perceberem a sua realidade e para o equacionamento e a resolução dos problemas de ordem técnica, econômica e social que envolve o cotidiano organizacional.

Para melhor entender essa dimensão dialógica se faz necessário recuperar o apelo de Habermas (1981) na sua teoria de ação comunicativa, quando contrapõe a racionalidade técnica à racionalidade prática. Mesmo reconhecendo que na sociedade contemporânea a "racionalidade instrumental" (técnica) exerce seu domínio de maneira soberana e anuncia o triunfo dos meios sobre os fins, valorizando sempre o "como?" e não o "por que ?" das coisas, percebemos que a ação comunicativa envolve um processo de compreensão longa e por todas as pessoas, dos fins a serem alcançados com uma clara tendência à ação. Para Habermas (1981) somente é possível se chegar a acordos genuínos e justos quando os participantes têm relação de poder simétrica e, ao negociarem, apresentam argumentos possíveis de questionamento a crítica pelo outro, mas que podem ser reafirmados ou refutados com fundamentações racionais.

A grande contribuiçãao do autor para se refletir sobre a comunicação organizacional, é que todo processo comunicativo se sustenta na base do diálogo, permitindo a qualquer dos participantes da interação ou negociação poder e direitos iguais de questionar o outro sem recorrer à coerção. Essa igualdade de "poder e direitos" não significa simetria de desejos e propósitos iguais, mas possibilidades e abertura na negociação para que possíveis diferenças e conflitos sejam expostos devidamente acompanhados das razões que o sustentam (VIZEU, 2003; CARDOSO, 2006; FOSSÁ, 2003).

Assim, quando se fala em comunicação, há que se destacar que ela ainda é um desafio para as organizações, mas o certo é que a busca por uma comunicação excelente deve constituir uma meta a ser alcançada pelos que a dirigem no cotidiano das organizações (KUNSCH, 2009). Ou seja, nas palavras da autora, a comunicação viabiliza-se graças à comunicação que existe em seu interior, daí a importância e o peso da comunicação para uma organização. Desse modo, quando uma organização consegue perceber que a 
competição global, as transformações tecnológicas e as constantes mudanças nas necessidades do mercado em termos de produtos e prestação de serviços requerem uma força de trabalho comprometida com os objetivos da empresa e ágil na resposta às modificações que se processam em um ambiente de grande complexidade, tem utilizado a comunicação, a valorização, a motivação e a satisfação dos empregados como prioridades corporativas. Para assegurar esse compromisso, estabelece políticas para direcionar o relacionamento com os empregados e, em contrapartida, espera que os empregados trabalhem como parceiros da empresa, com lealdade e cooperação, assumindo a responsabilidade na entrega de seus outputs aos clientes e vontade de adaptação às condições de mudança do negócio.

A comunicação interna como atividade administrativa e estratégica gera capacidade de produção, de competição e de adaptação da organização frente ao ambiente em constante transformação. Muitos dos problemas organizacionais têm origem na má ou na inexistente administração da comunicação. Neste contexto, os canais de comunicação devem ser fortalecidos e ampliados. A comunicação interna pode ser compreendida como a forma de sistematizar informações, fazendo com que haja uma constante interação entre os colaboradores de uma determinada organização. Ela tem o poder de renovar e transformar ambientes, humanizar as relações entre os indivíduos, criar clima favorável, melhorar relações de trabalho, dar vida à constante acomodação das empresas e ajustar comportamentos. A comunicação gera influências e transforma-se, sem dúvida, no principal valor de crescimento e adaptação empresarial.

Uma vez entendido que não são os produtos que diferem uma organização da outra, mas a forma como elas se relacionam com os públicos, a comunicação organizacional passa a ser utilizada como estratégia de negócios. Ao moldar-se à cultura organizacional, a comunicação se constitui em um poder expressivo para alavancar as mudanças e contextualizar a organização no mercado, em suas dimensões política, econômica, social e tecnológica.

No plano político, as organizações podem desenvolver ações no sentido de conscientizar os funcionários sobre a importância do trabalho em equipe, do compromisso com a satisfação dos requerimentos dos clientes internos e externos, do envolvimento com a comunidade e da prática da cidadania. No plano social, desenvolver uma série de atividades voltadas para despertar nos funcionários o espírito para o exercício da cidadania, através de ações comunitárias, visando melhorar e conferir mais qualidade à vida 
das pessoas. Essas ações de caráter social assumem uma característica não de assistencialismo, pois ele acaba gerando uma dependência da comunidade perante qualquer tipo de ajuda, seja do governo ou da iniciativa privada, mas como uma forma de gerar o desenvolvimento auto-sustentado de uma comunidade.

No plano econômico, podem agir em consonância com os requerimentos do consumidor e para tanto desenvolver formas para ouvir o cliente, tais como pesquisa de satisfação de clientes. Também promover e divulgar a visão de futuro da organização, treinar, educar, e preparar o funcionário a obter desempenho para a melhoria contínua dos processos que desembocam no cliente. Desenvolver ações voltadas para o conceito de segmentação e personalização nas relações. Já, no plano tecnológico, redimensionar constantemente os seus sistemas operacional e de produção com o objetivo de obedecer aos princípios da qualidade, da produtividade e da competitividade. Sua prática de comunicação incorpora os requerimentos internos e externos, criando canais que favoreçam a relação da empresa com os empregados, clientes e a sociedade, de forma ágil, pró-ativa, transparente e ética.

Dentre tantas atividades que a comunicação no ambiente organizacional realiza, certamente, a comunicação interna é uma das mais importantes, porque, por meio dela ocorre a integração entre os processos de gestão e, também, a troca de conhecimentos e de informações entre líderes e colaboradores. Corrêa (2008) destaca que

[...] gerenciar relacionamento é função básica de relações públicas e isso implica em entendimento e comprometimento para uma atuação estratégica, impactando diretamente na produção de uma realidade organizacional integrada à identidade, imagem e reputação, perante os diversos públicos da organização (CORRÊA, 2008, p. 9).

Ao gerenciar relacionamentos, o profissional de Relações Públicas precisa estabelecer uma comunicação simétrica, pois esse modelo se baseia em princípios de negociação e compromisso e tem como principal objetivo a compreensão mútua entre os sujeitos. Assim, podemos inferir que a compreensão mútua almejada pelo modelo simétrico demanda a existência de ambientes participativos, onde prevaleçam o debate e o diálogo entre os sujeitos. Conforme salienta Grunnig e Hunt 
[...] as relações públicas simétricas propiciam um foro para o diálogo e a discussão de questões que levarão a resultados divergentes em razão de participarem pessoas com diferentes valores e pontos de vista. Os resultados devem ser éticos, mesmo não se ajustando ao sistema de valores de forças rivais, quando o dialogo está estruturado na base de regras éticas (GRUNIG; HUNT, 2003, p. 88).

Para Grunig e Hunt (2003) o princípio de simetria significa que os valores e problemas das organizações e dos públicos são ambos relevantes. Para o autor, o diálogo faz com que as Relações Públicas sejam inerentemente éticas e que a organização seja mais responsável para com a sociedade. Bueno (2011) complementa dizendo que "a comunicação no ambiente de trabalho precisa ser transparente e verdadeira", ou seja, aquilo que se fala precisa ser igual ao que se pratica baseado na participação, na liberdade de expressão e no respeito à individualidade de cada um. É sob a ótica da responsabilidade e seriedade que se vislumbra a atuação do Relações Públicas nas empresas, tendo o profissional a capacidade de interagir com os diferentes stakeholders, com uma linguagem compreensível, autoridade necessária e, a cima de tudo, com uma postura que inspire confiança e idoneidade.

O desafio de implementar essa visão não é tarefa fácil, em especial para alguns gestores que não possuem o conhecimento sobre quanto esse tipo de ação é essencial. "Muitos simplificam o processo e ignoram o potencial da comunicação interna como estratégia de integração e valorização das pessoas" (CASTRO, 2014, p. 80). Assim como quem consome os produtos porque confia na empresa, os funcionários precisam ser conquistados para executarem as suas funções com a mesma confiança. De acordo com Freitas (2009), essa prática de comunicação vai muito além do que apenas criar uma interação entre as partes, ela pressupõe um conjunto de disposições verbais e não verbais que se exprimem por palavras e que buscam o diálogo e a sinergia das relações entre as pessoas. Por mais recursos financeiros que a organização possua, por mais moderno que seja o setor de comunicação, o diálogo precisa gerar um significado real ao funcionário. Assim, o conceito que os líderes devem ter sobre essa prática é fundamental, pois, através dela, os vínculos poderão ser estabelecidos. Seguindo esse mesmo raciocínio, Gonçalves (2010, p. 46) aponta que

Ao implantarem sistemas de comunicação interna simétrica as organizações possibilitam a participação de todos os públicos in- 
ternos no processo de tomada de decisões. Além disso, os objetivos dos empregados são integrados na missão organizacional e a comunicação simétrica com os empregados permite aumentar a satisfação no trabalho.

Por isso tudo, a comunicação interna precisa resgatar valores, crenças e identidades ao ampliar o escopo da pesquisa de clima interno e não se limitar a medir apenas satisfação e insatisfação no trabalho. Investigar como os funcionários veem a empresa, o conhecimento que tem dela e da sua inserção no mercado, o discernimento que possuem sobre os principais concorrentes e das estratégias utilizadas para se relacionar com o mercado, as características diferenciais em relação à concorrência, as mudanças que estão ocorrendo no mercado e como a organização está se preparando para enfrentá-las e tantos outros fatores que povoam o mundo dos negócios.

\section{INTERFACES DA COMUNICAÇÃO INTERNA COM A GESTÃO DE PES- SOAS}

Com tantas opções na comunicação interpessoal, as empresas estão cada vez mais em busca de como adaptar-se e tornar o ambiente de trabaIho agradável, que proporcione crescimento pessoal e profissional. Por isso, as organizações estão revendo o papel das pessoas e da própria organização nessa relação delicada, mas necessária. De acordo com Dutra (2009), a comunicação "[...] deve ser integrada e o conjunto de políticas e práticas que a formam deve, a um só tempo, atender aos interesses e expectativas da empresa e das pessoas. Somente dessa maneira será possível dar sustentação a uma relação produtiva entre ambas" (2009, p. 16). Outro ponto importante a ser destacado é que estamos falando de pessoas e, dentro de uma organização, "cada uma têm sua maneira de realizar as tarefas que lhes competem e é neste ponto que a gestão de pessoas deve oferecer metodologias que permitam à pessoa desenvolver-se por si mesma para entregar o que lhe é demandado" (DUTRA, 2009, p. 22).

Gerir pessoas nas organizações, como apontam Mósca, Cereja e Bastos (2014), é lidar "com diferentes individualidades, interesses, aspirações e idiossincrasias e direcioná-los ao serviço de um interesse comum, o da organização a qual pertencem" (2014, p. 26). Isto significa dizer, seguindo os mesmos autores, que a gestão de pessoas não pode ser tratada pela orga- 
nização como um conjunto de atividades isoladas. Ela deve, sempre, estar alinhada à razão de ser da organização, a sua missão e os seus objetivos estratégicos.

Nassar (2009) afirma que as organizações possuem suas normas, regulamentos e sistemas e eles devem ser entendidos pelas pessoas as quais fazem parte da mesma e, neste ponto, a comunicação é fundamental para que a administração organizacional - políticas, planejamentos, ações, coordenações, direções e controles - tenham sentido e significado para os integrantes da organização e de suas redes de relacionamento.

Nas palavras de Kunsch (2003), a comunicação interna também se faz fundamental e somente terá eficiência se houver um trabalho de equipe entre as duas áreas, se houver envolvimento das diretorias e dos colaboradores e, o mais importante, segundo a autora, se houver um planejamento adequado e consistente. Desse modo, a gestão de pessoas deve estar sempre de acordo com a estratégia da organização e, assim, "a comunicação é a sua principal aliada, na medida em que vai refletir o modelo organizacional existente naquele contexto" (MÓSCA; CEREJA; BASTOS,2014, p. 117).

Gerir pessoas trata-se de uma função gerencial que visa à cooperação das pessoas que atuam nas organizações para o alcance de objetivos, tanto organizacionais quanto individuais Estruturar esse sistema de gestão, que envolva valores, sejam da empresa ou pessoais, também exige cuidados para que os gestores e o quadro funcional valorizem essa nova maneira de relacionamento entre ambos. De acordo com Argenti (2011, p. 19), "transformar isto em comportamento generalizado exige novos tipos de liderança, instrumentos e habilidades". Hoje, dá-se uma atenção especial para a gestão de pessoas e esse desenvolvimento deve ser planejado com cautela. Dutra (2009) explica porque é fundamental esse entendimento.

As organizações estão cada vez mais pressionadas, tanto pelo ambiente externo quanto pelas pessoas com as quais mantêm relações de trabalho, para investir no desenvolvimento humano. As organizações estão percebendo a necessidade de estimular e apoiar o contínuo desenvolvimento das pessoas, como forma de manter suas vantagens competitivas. Ao mesmo tempo, as pessoas buscam seu contínuo desenvolvimento para obter mais segurança quanto a sua inserção no mercado de trabalho (DUTRA, 2009, p. 101).

A gestão da comunicação interna, assim como os outros setores, precisa 
ser bem planejada, com destaque para o cuidado e a responsabilidade em conduzir os funcionários dentro das ideias propostas para torná-los cada vez mais parte do todo. Na visão de Guedes (2007), a comunicação interna seria uma espécie de conciliadora entre os interesses de gestores. Por meio dela cria-se um ambiente de trabalho mais harmonioso, saudável e também a identidade da organização é criada.

Com isso, verifica-se a necessidade de novas práticas de gestão de pessoas, através de uma reflexão sobre a forma de pensar e agir das organizações. Para além disso, é preciso considerar um posicionamento no qual a comunicação tem papel fundamental na gestão de pessoas. Logo, vislumbra-se, na comunicação, um forte recurso agregador, contribuindo para o fortalecimento dos indivíduos em relação ao seu trabalho e ao seu lugar na estrutura da organização.

Parte de Kunsch (2003) a premissa de que o RP deve estabelecer um trabalho integrado nas diversas habilidades da área com uma visão macro, ampla e mediando o processo da comunicação interna. A sua função é administrar o fluxo de informação, pois tem o caráter de desenvolver relacionamentos que resultem em benefícios mútuos para todas as partes envolvidas.

\section{METOdologiA, OBJeto E discussões}

Esta seção visa analisar a intersecção da comunicação interna com a gestão de pessoas para o desenvolvimento de processos de comunicação mais integrados, participativos e com foco nas pessoas, buscando compreender como o trabalho de Relações Públicas pode ser fator preponderante na mediação da comunicação interna no ambiente organizacional. Utiliza-se o caso da Sicredi Região Centro como unidade de análise que nos permitirá enxergar a articulação entre a teoria e a prática diária das organizações.

\section{PROCEDIMENTOS METOdOLÓGICOS}

A pesquisa enquadra-se como exploratória e teve, como instrumento principal para a coleta de dados, a observação não-participante e a entrevista em profundidade. A observação assumiu a configuração de não-participante, uma vez que as pesquisadoras se mantiveram apenas na posição de observadores não se envolvendo diretamente com o objeto empírico. A partir desse processo, foi possível estar mais próximo à empresa, presenciando fatos e realidades, conhecendo um pouco mais do cotidiano da $\mathrm{Si}$ credi Região Centro. 
Além da observação não-participante, a entrevista em profundidade partiu de um roteiro de questões semi-estruturado, onde foram coletadas informações abrangendo os aspectos relevantes no que tange à área de gestão de pessoas e à área de comunicação e marketing da empresa. As entrevistas foram realizadas no primeiro semestre de 2016, na sede da Superintendência Regional da Sicredi Região Centro, em Santa Maria (RS).

$O$ roteiro utilizado para as entrevistas em profundidade contemplou seis dimensões centrais que foram acrescidas de outras informações que surgiram ao longo das observações realizadas. Com relação as seis dimensões definidas, elas foram baseadas no referencial teórico proposto para o estudo. Essas dimensões serviram como suporte para que fosse possível um maior conhecimento da empresa e de suas experiências nas áreas de gestão de pessoas e comunicação interna. As seis dimensões estão dispostas no Quadro 1.

Quadro 01: Dimensões de análise

\begin{tabular}{|l|l|l|}
\hline & \multicolumn{1}{|c|}{ Dimensão } & \multicolumn{1}{c|}{ Descrição } \\
\hline I & Informações do entrevistado & $\begin{array}{l}\text { Conhecer quem são os profissionais que } \\
\text { estão à frente das áreas de comunicação } \\
\text { e marketing e gestão de pessoas. }\end{array}$ \\
\hline II & Percepções gerais & $\begin{array}{l}\text { Entender de que maneira a empresa enx- } \\
\text { erga as suas "pessoas" e de que forma cri- } \\
\text { am-se as relações no âmbito organizacio- } \\
\text { nal. }\end{array}$ \\
\hline III & Percepções sobre a empresa & $\begin{array}{l}\text { Compreender se as ações realizadas pelas } \\
\text { duas áreas precisam estar pautadas sobre } \\
\text { a missão e valores da empresa e de que } \\
\text { forma os gestores percebem a função de } \\
\text { ambos. }\end{array}$ \\
\hline IV & Gestão de Pessoas & $\begin{array}{l}\text { Entender de que forma a área trabalha, } \\
\text { separadamente ou aliado à comunicação } \\
\text { interna, e se este é um elemento que a } \\
\text { empresa usa para estar mais perto de } \\
\text { seus colaboradores. }\end{array}$ \\
\hline V & Comunicação Interna & $\begin{array}{l}\text { De que forma a área trabalha, separada- } \\
\text { mente ou aliado à gestão de pessoas, e } \\
\text { se este é um elemento que a empresa usa } \\
\text { para estar mais perto de seus colabora- } \\
\text { dores. }\end{array}$ \\
\hline
\end{tabular}




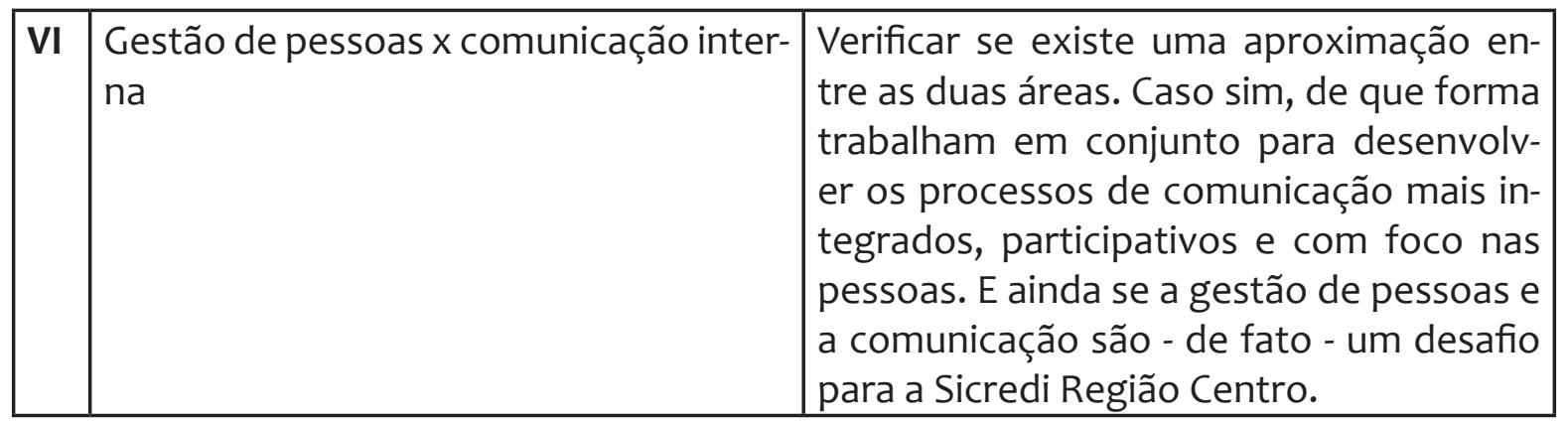

Fonte: Elaborado pelas autoras, com base na fundamentação teórica proposta

Optou-se, portanto, que as entrevistas fossem realizadas com a responsável pela área de comunicação e marketing e com a responsável pela área de gestão de pessoas da empresa. A primeira entrevista foi realizada com a assessora de comunicação e marketing que é formada em Relações Públicas pela UFSM e há 12 anos faz parte do quadro de colaboradores da Sicredi Região Centro. A segunda entrevista foi realizada com a assessora de gestão de pessoas que tem formação em Psicologia pelo Centro Universitário Franciscano (Unifra) e há oito anos integra o grupo de colaboradores da Sicredi Região Centro.

\section{O OBJETO DE ESTUDO}

A Sicredi, de modo amplo, é uma instituição financeira cooperativa, criada há mais de 100 anos no Brasil, presente em 11 Estados brasileiros. Hoje, a Sicredi conta com quatro centrais regionais - acionistas da Sicredi Participações S.A., uma Confederação, uma Fundação e um Banco Cooperativo e suas empresas controladas. Os mais de três milhões de associados votam e decidem sobre os rumos da sua cooperativa de crédito, sendo esse o modelo de gestão que valoriza a participação e que segue o slogan "feito por pessoas e para pessoas".

A missão da Sicredi, como sistema cooperativo, é valorizar o relacionamento, oferecer soluções financeiras para agregar renda e contribuir para a melhoria da qualidade de vida dos associados e da sociedade. Os valores da empresa são: preservação irrestrita da natureza cooperativa do negócio; respeito à individualidade do associado; valorização e desenvolvimento das pessoas; preservação da instituição como sistema; respeito às normas oficiais e internas; eficácia e transparência na gestão.

No momento em que a empresa apresenta-se tendo como diferencial um modelo de gestão que valoriza a participação, é possível depreender 
que, assim como os mais de três milhões de associados votam e decidem sobre os rumos da sua cooperativa de crédito, os colaboradores também têm uma participação muito ativa em decisões de nível micro e macro.

Vale destacar que no prédio da Superintendência, funciona o Conselho de Administração (Presidente, Vice e Conselheiros), Diretoria Executiva (Diretor Executivo, Diretoria de Negócios e Diretoria de Operações). Todos os demais cargos estão sob a gestão dessas áreas. Ao todo, 67 colaboradores atuam na sede da Superintendência da Região Centro, em Santa Maria (RS).

\section{RESULTADOS E DISCUSSÕES}

A partir da categorização exposta na metodologia, o conteúdo analisado foi organizado de acordo com a área de atuação das profissionais entrevistadas. A saber: comunicação e marketing e gestão de pessoas.

Especificamente quanto a área de comunicação e marketing, pode-se entender que, entre as principais funções no setor, estão assessoria de imprensa, relações com a mídia, planejamento, organização de feiras e eventos, mídias sociais, padronização de unidades, branding, comunicação corporativa, plano de marketing, marketing direto, além do endomarketing, que engloba a apresentação de novos colaboradores e o gerenciamento de grupos internos nas redes sociais como Facebook, Whatsapp e, ainda, por e-mail.

Para a assessora de comunicação e marketing os múltiplos papéis de um assessor dentro da empresa são intensos e dinâmicos. Nas palavras dela, o trabalho precisa estar sempre em aperfeiçoamento, buscando as tendências que estão disponíveis no mercado. O desafio é sempre surpreender, pelo fato do público interno criar muita expectativa a cada nova ação, justamente por saber que o setor sempre apresenta algo diferente. A assessora destacou ainda que, ao final de cada ação, a área realiza uma pesquisa de avaliação sobre os pontos positivos e negativos e sobre o que os colaboradores esperam das próximas atividades. Isso corrobora a ideia de que a atividade de comunicação dentro das organizações não pode ser vista da maneira tradicional. Kunsch (2003) aponta que os indivíduos que fazem parte das organizações comunicam-se e interagem de diversas formas e é o que se pode verificar na fala da entrevistada.

Sobre a relação da Sicredi Região Centro com suas pessoas, a assessora de comunicação e marketing afirmou que o colaborador é a força de trabalho e que existe a preocupação em incentivá-lo, cada vez mais, através 
de ações e também do oferecimento de benefícios como plano de carreira, campanhas de incentivo, planos de saúde e estímulos para qualificação. Ou seja, a empresa ajuda no custeio de cursos de pós-graduação, língua estrangeira e qualificação em cursos e eventos. Isso demonstra que a valorização do colaborador é um ponto relevante para a empresa.

Quanto a forma com que ela percebe a gestão da comunicação na Sicredi Região Centro, a assessora afirmou que foi uma evolução, pois até chegar ao nível estratégico de atuação em que a empresa se encontra hoje, passou-se por diversas realidades. Na mesma linha de pensamento, a assessora reforçou que todas as estratégias são pensadas não somente na área de comunicação e marketing, mas em todas as outras áreas e que elas precisam estar alinhadas com a missão e os valores da empresa. Hoje, por exemplo, a empresa está elaborando o seu planejamento estratégico para os próximos quatro anos e, desse processo, participam gestores, assessores, diretores, gerentes em um total de 26 pessoas. A equipe foi dividida em quatro grupos, cada um na sua linha de atuação. Isso comprova o que Mósca; Cereja; Bastos (2014) dizem quando referem que os setores de gestão de pessoas e comunicação precisam estar alinhados, pois cada colaborador possui o seu jeito, a sua individualidade e para que todos cheguem a um mesmo objetivo, a empresa precisa comunicar qual linha estratégica adota e por quais objetivos o colaborador trabalhará.

Ainda na dimensão acerca das percepções sobre a empresa, a assessora apontou que a área de comunicação e marketing trabalha em interface com outras diretorias, como a de negócios e operações, mas não tem autonomia para decidir quais ações realizará, ou seja, tudo é compartilhado em reuniões que acontecem semanalmente, onde todas as propostas de ação são apresentadas e discutidas para, assim, executar o que foi decidido para cada área. Cabe salientar também que a área de comunicação e marketing e a de gestão de pessoas respondem diretamente ao diretor executivo da unidade. Pelas palavras da assessora, isso só vem reforçar que o planejamento de forma clara e eficiente é fundamental para a boa comunicação entre todas as áreas, independente da hierarquia. Nassar (2009) salienta que, além de um bom planejamento, esse tipo de ação precisa ter sentido para os que as fazem e para os que as recebem.

Com relação ao posicionamento dos gestores sobre o trabalho desenvolvido pela área de comunicação e marketing, a assessora apontou que existem diferentes percepções, pois nem todos têm a real dimensão do que 
é feito, mas que também houve uma evolução no ponto de vista deles. Utilizando as palavras da assessora, "nem todos têm a noção do que é a função. Alguns sabem e outros não têm a preocupação em saber o que realmente o setor realiza". Logo, pode-se perceber que a forma com que a comunicação vem sendo vista nas organizações ainda está em pleno desenvolvimento e, de acordo com a assessora, isso acontece no dia a dia e a empresa está longe de chegar a um consenso comum, pelo fato de muitos gestores (que são o meio entre o setor e os colaboradores), ainda que percebam a atividade como positiva, não compreendem por completo a sua real função.

Guedes (2007) afirma que as empresas estão percebendo que a comunicação é uma ferramenta indispensável, principalmente para o diálogo entre as hierarquias. Por outro lado, a fala da assessora também vai ao encontro do que destaca Corrêa (2008) quando afirma que o diálogo, mesmo sendo uma das principais ferramentas para que a comunicação aconteça com clareza, não é aceito por alguns gestores e, por isso, cada vez mais, o papel da comunicação e da gestão de pessoas precisa fazer-se presente nas organizações, como, de fato, acontece com a empresa que foi o objeto de estudo desta pesquisa.

A quarta dimensão abordou a percepção da entrevistada em relação a sua área de trabalho. Neste ponto, a assessora pontuou que o seu trabalho é um desafio diário, pelo fato de a sua função ser dinâmica e ter sempre que oferecer algo novo para o colaborador (ações) e para os gestores (projetos). Sobre a maneira como a empresa 'fala' com os colaboradores, a assessora afirmou que, antes da execução de qualquer ação, busca-se colocar no lugar do outro, de que forma aquela mensagem impactará e/ou qual relevância ela terá para os indivíduos envolvidos. Para isso, o setor tenta reconhecer e valorizar sempre a figura do colaborador, a partir de ações que o torne cada vez mais parte da empresa e tudo isso ocorre através do diálogo aberto. Segundo a assessora, hoje, a empresa possui foco em ações nas redes sociais digitais, como Facebook e grupos de WhatsApp. Pelas redes sociais, estão à disposição fotos dos eventos realizados, divulgação de novas oportunidades, vídeos como, no caso das comemorações referentes ao mês da muIher, a partir da campanha "Sicredi Mulher", entre outras ações. No app de mensagens, são criados grupos com os colaboradores e também grupos de gestores em que há grande compartilhamento de informações. Utilizando as palavras da assessora, "a empresa busca estar onde o colaborador está". Essa nova maneira de comunicar-se vai muito além das paredes da empresa, 
ela cria espaços de convivência, redimensiona hábitos de consumo e circulação de informações como bem salienta Bueno (2011). Fica evidente, portanto, que o papel do assessor de comunicação dentro da empresa faz-se necessário, pois, através de seu trabalho, surgem relações para além de chefe x funcionário. De acordo com Guedes (2007), é através da comunicação mais aberta que surgem as oportunidades para os diálogos menos formais.

Na última dimensão proposta que pontuou questões relacionadas às duas áreas (comunicação interna e gestão de pessoas), na percepção da assessora, existe uma aproximação muito clara, pois, além de responderem para o mesmo Diretor Executivo, não conseguem realizar as tarefas por completo se não estiverem atuando em conjunto. As duas áreas trocam muitas ideias e estão sempre em contato. Segundo a assessora, 90\% dos colaboradores identificam-se com os valores e a missão e, portanto, o trabalho que é realizado de forma integrada com a gestão de pessoas é importante para que esse número continue a crescer.

Sobre a comunicação interna e a gestão de pessoas serem um desafio para a Sicredi Região Centro, a assessora afirmou que se trata de um desafio diário, uma vez que o foco do trabalho de ambas as áreas é justamente as "pessoas". A partir da fala da assessora, pode-se inferir que mesmo com todos os recursos, sejam eles tecnológicos ou financeiros, se não houver um compartilhamento de informações simultâneo, o trabalho de ambas as áreas pode ser comprometido. Entender de que forma o colaborador gostaria de ser tratado, envolvê-lo nos princípios da empresa e fazer com que se sinta parte da organização é uma tarefa da área de comunicação que, segundo Argenti (2011), sendo realizada com êxito, cria o laço de confiança e pertencimento entre colaborador e empresa.

Quanto à área de gestão de pessoas, os múltiplos papéis de sua atividade são um desafio, justamente por ter que se relacionar bem com todas as áreas e ter uma aceitação por parte dos gestores e tudo isso precisa ter uma entrega com qualidade, impactando positivamente o colaborador que está na outra ponta.

Na segunda dimensão, que se referiu às percepções gerais dos colaboradores, a assessora contou que o "jeito" Sicredi de trabalhar já diz muito sobre como a empresa percebe os seus colaboradores, pois o trabalho é “de pessoas para pessoas”. Segundo ela, há uma preocupação genuína de bem-estar e satisfação, que fica comprovada em números: pelo quinto ano consecutivo, o Sicredi é uma das 150 melhores empresas para trabalhar no 
Brasil. A Sicredi Região Centro "cuida" desde a chegada de um novo colaborador até eventos com datas especiais (Dia das Mães, dos Pais, da Mulher). Tudo é planejado para que cada vez mais o colaborador sinta-se parte da empresa, por isso, o cuidado é diário. Isso só comprova que há uma integração entre colaboradores e instituição, no momento em que a empresa proporciona ações para que o colaborador trabalhe com empenho e para construir uma imagem positiva da marca. Com isto, os colaboradores sentem-se parte do processo o que, conforme Corrêa (2008), passa a ser uma crença nos valores expressos pela instituição.

Sobre as políticas de gestão de pessoas desenvolvidas pela empresa, a assessora destacou que a preocupação que o Sicredi tem em poder contar com as pessoas e participar desses processos traz um grau de pertencimento. Na pesquisa de clima, por exemplo, que é feita de dois em dois anos, os resultados mostram o alto nível de envolvimento e do gosto que os colaboradores têm em fazer parte da empresa. Na mesma linha, a assessora expôs que por trabalhar diretamente com os gestores, o seu papel é orientá-los no repasse das informações aos colaboradores e citou, como exemplo, o lançamento de campanhas internas em que os gestores comunicam aos seus subordinados as informações repassadas pelo próprio setor de gestão de pessoas.

Quanto às percepções gerais da empresa, a assessora pontuou que a Sicredi Região Centro possui um modelo de gestão de pessoas que é sistêmico, vinculado com a missão e os valores da empresa, e, ainda assim, o setor possui autonomia para pensar ações e executá-las junto aos gestores, a partir de suas próprias demandas. Sobre a maneira como os colaboradores são motivados, a assessora ressaltou que os benefícios são muitos, entre eles, a ajuda de custo para os que desejam ter uma melhor qualificação profissional, os benefícios em saúde e alimentação, entre outros. O Programa de Participação nos Resultados (PPR) também é uma forma de valorizar o colaborador na questão financeira. Sobre a sua percepção a respeito da gestão de recursos humanos, a assessora disse que pode melhorar, ou seja, é uma construção diária e a cada novo desafio, isso fica evidente. Fica claro, aqui, que isso só é possível através de um bom relacionamento entre a sua área e a da comunicação, o que de, acordo com Marchiori (2010), é aí que se constroem as relações internas para que os objetivos da empresa e do colaborador sejam alcançados.

Antes da gestão de pessoas assumir esse papel estratégico de cuidado 
e atenção com os colaboradores, a área era vista apenas como aquela que apenas admitia/demitia. Até conseguir chegar à configuração atual, a assessora contou que foram necessárias algumas modificações em termos de competências, habilidades e um reposicionamento interno, pois foi preciso entender o que, de fato, era estratégico, inclusive atribuições dos colaboradores e tudo foi sendo testado com o passar do tempo. Como a área mexe com a individualidade das pessoas, ao ser questionada sobre como a gestão de pessoas consegue mostrar-se parceira de gestores e colaboradores e não como apenas um setor burocrático, a assessora destacou que os gestores precisam compreender o propósito da gestão de pessoas, qual a necessidade de ter o setor na Sicredi Região Centro, para, assim, conseguirem comunicar-se com eles. Observa-se, aqui, que a empresa tem a preocupação em melhorar cada vez mais essa relação, fazer com que a gestão solidifique-se perante os colaboradores. Por outro lado, conforme Castro (2014), muitos gestores não dão a devida importância para esse processo tão fundamental para o seu próprio desenvolvimento dentro da empresa.

É necessário fazer-se a leitura do cenário em que se quer comunicar e, nisso, a assessoria de comunicação e marketing é fundamental, segundo a assessora. Se a gestão de pessoas é um desafio para a Sicredi, ela afirmou que sim, pois, a cada dia, é um novo desafio que surge, tudo é uma evolução.

Na quinta dimensão que abordou a questão do relacionamento entre os dois setores (comunicação e marketing e gestão de pessoas), a assessora reforçou que há uma aproximação saudável e necessária entre as áreas, pelo fato de trocarem muitas informações e as suas funções completarem-se. A assessora contou que esse é apenas um dos muitos motivos pelos quais a atuação dos dois é muito próxima, pois todas as ações das áreas são praticamente juntas. Fica evidente, portanto, que a gestão de pessoas é a principal aliada da comunicação e vice-versa, pois ambas transparecem o modelo de gestão da organização. Mósca, Cereja e Bastos (2014) reiteram que é fundamental as empresas terem essa preocupação de alinhar todos os processos oferecidos pela comunicação junto com todas as práticas de gestão de pessoas que possam ser aplicadas no âmbito da organização.

Segundo a entrevistada, os passos precisam estar alinhados e não há como ser diferente, uma vez que "para fazer as coisas acontecerem, precisamos das pessoas, mas para efetivamente podermos ter resultados, precisamos comunicar para as pessoas e não há como fazer isto sem a parceria da comunicação e do marketing”. Existem coisas específicas de cada seto, 
porém a execução de quase todas as atividades completa-se. Logo, depreende-se que são as pessoas que precisam ser a motivação das organizações e, neste sentido os autores pesquisados pontuam sobre o cuidado e a atenção que as organizações precisam ter com os seus colaboradores e isso é demonstrado em investir em comunicação e em gestão de pessoas, conforme salientou a assessora da área de gestão de pessoas ao dizer que os gestores recorrem para o setor justamente para poderem dialogar com mais clareza com os colaboradores, por se preocuparem com as suas pessoas.

Quanto à relação com os gestores, a assessora reforçou que também é uma construção diária, pois as percepções evoluíram muito ao longo do tempo. No caso da área de gestão de pessoas, os gestores procuram-na para tirar as suas dúvidas e pedir auxílio, por exemplo, para saber qual a meIhor forma de conversar com o colaborador. Segundo a assessora, o diálogo mais aberto entre as hierarquias é o resultado de um trabalho constante da área com os gestores sobre a forma com que devem comunicar-se com os seus subordinados.

Sobre os setores acompanharem os novos modelos e métodos que surgem no mercado nas áreas de comunicação e gestão de pessoas, a assessora assinalou que o próprio modelo de gestão de pessoas da Sicredi foi pensado visando às ações que acontecem no mercado. Há um cuidado para estarem sempre acompanhando essas mudanças. Neste contexto, a assessora não vê a possibilidade de trabalhar com as duas áreas afastadas, pois a gestão precisa do "braço" da comunicação e do marketing, salienta a entrevistada. Verifica-se tanto pelas palavras da assessora quanto dos argumentos de Dutra (2009), que as instituições passaram a preocupar-se mais com o que o mercado estava fazendo para "cuidar de suas pessoas" e isso fez com que a gestão de pessoas buscasse maneiras eficientes para unir os interesses das empresas e de seus colaboradores.

Sobre se as práticas de gestão estão relacionadas com as transformações ocorridas na Sicredi Região Centro ao longo do tempo, a assessora afirmou que sim, porque houve uma mudança de visão da empresa sobre os conceitos dessas áreas. Na mesma linha, quando questionada se os setores executam funções essenciais na Sicredi Região Centro, disse que sim, porque as duas áreas são imprescindíveis, uma vez que cuidam de mais de 300 colaboradores e, mesmo com tantas pessoas envolvidas, o nível de satisfação dos colaboradores é positivo. Segundo ela, "implantar as políticas de gestão de pessoas e da comunicação, criar os melhores estímulos, as me- 
Ihores práticas e, principalmente, ter bons resultados é um grande desafio."

A partir do relato das experiências da Sicredi Região Centro, pode-se reunir uma série de elementos que permitem realizar uma reflexão sobre o trabalho de Relações Públicas como parte do processo de gestão das organizações. A atuação de profissionais de RP junto a profissionais da área de gestão organizacional permite a otimização dos processos de comunicação e relacionamento das organizações contemporâneas com os seus públicos de interesse.

Em relação a Sicredi Centro, observa-se que a empresa está, cada vez mais, valendo-se da gestão de pessoas e do trabalho de comunicação, como atividades próximas, para um melhor relacionamento com os seus públicos, já que as duas áreas trabalham para unir a alta direção com os seus públicos, visando obter resultados positivos e que agreguem valor à organização.

\section{CONSIDERAÇÕES FINAIS}

O objetivo deste estudo foi realizar uma articulação entre a teoria e a prática diária das organizações, buscando observar como a comunicação interna pode atuar junto à gestão de pessoas das empresas para o desenvolvimento de processos de comunicação mais integrados e participativos, tendo o trabalho de Relações Públicas como parte do processo de gestão nas organizações.

Para isto, buscou-se conhecer as experiências da Sicredi Região Centro que mantém uma área de comunicação e marketing, liderada por uma profissional de Relações Públicas trabalhando em conjunto com a área de gestão de pessoas. A partir das experiências positivas da Sicredi Região Centro, foi possível inferir que a empresa consegue uma aproximação entre as áreas de comunicação e marketing e gestão de pessoas e, ainda, que o colaborador é parte importante no dia a dia da atividade dos setores e, principalmente, de toda a empresa. Por outro lado, entende-se que, em termos de gestão de pessoas e de comunicação interna, nem todas as empresas possuem o mesmo viés institucional da Sicredi Região Centro e nem esse posicionamento com relação à postura e à atuação dos gestores no que se refere à sua conduta perante os colaboradores.

Por meio dos resultados obtidos na pesquisa empirica, é possível perceber que a aproximação entre as áreas viabiliza uma melhor intermediação e administração de relacionamentos no ambiente organizacional. Essa prática eleva o potencial das Relações Públicas como mediadora da comunicação 
nas organizações e abre uma nova perspectiva para a inserção desses profissionais no mercado.

A pesquisa sinaliza que a atividade de Relações Públicas tem como função criar, desenvolver e manter a comunicação com os públicos da organização e vice-versa; estabelecer canais que possibilitem o relacionamento entre os públicos; atuar de acordo com a administração estratégica, sendo uma condição para a eficácia organizacional. Da mesma forma infere-se que a comunicação interna efetiva-se se for encarada como parte da cultura organizacional, apoiada pela alta direção e composta por atividades contínuas. A comunicação interna possibilita aos gestores comprometer as equipes, agilizar o fluxo informativo, fidelizar o quadro interno e formar uma equipe autêntica.

\section{REFERÊNCIAS}

ARGENTI, Paul A. Comunicação empresarial. Rio de Janeiro: Elsevier, 2011.

BUENO, Wilson da Costa. Comunicação Empresarial: políticas e estratégias. São Paulo, SP: Saraiva, 2009.

. Rádio Peão, redes sociais e a democracia na comunicação interna. Revista da Faculdade de Administração e Economia (ReFAE) da Universidade Metodista de São Paulo. Vol. 2, $n^{\circ}$ 2. 2011. Disponível em:<https://www.metodista.br/revistas/revistasims/index. php/ReFAE/article/view/2487/2446> Acesso em: 20 jan. 2016.

CARDOSO, Onésimo de Oliveira. Comunicação empresarial versus comunicação organizacional: novos desafios teóricos. Rev. Adm. Pública [online]. 2006, vol.40, n.6, pp.1123-1144. Disponível em: < http://www.scielo.br/scielo.php?script=sci_arttext\&pi$d=S 0034-76122006000600010>$ Acesso em: 15 nov. 2015.

CASTRO, Mônica Aparecida de. Comunicação Interna e Gestão de Pessoas: interfaces e perspectivas de integração e diálogo nas organizações. 2014. Dissertação (Mestrado em Comunicação Social) - Faculdade de Comunicações da Universidade Metodista de São Paulo, São Bernardo do Campo - SP. Disponível em:<http://ibict.metodista.br/tedeSimplificado/tde_busca/arquivo.php?codArquivo=3386>. Acesso em: 15 nov. 2015.

CORRÊA, Vera Elisabeth Damasceno. Comunicação Interna na gestão do relacionamento com os funcionários. 2008. Disponível em:<http://www.abrapcorp.org.br/anais2008/ gt2_damasceno.pdf>. Acesso em: 22 jan. 2016.

DUTRA, Joel Souza. Gestão de Pessoas: modelo, processos, tendências perspectivas. São Paulo: Atlas, 2009.

FOSSÁ, Maria Ivete Trevisan. A cultura de devoção em empresas familiares e visionárias - uma definição teórica e operacional, 2003. Tese (Doutorado em Administração). Universidade Federal do Rio Grande do Sul, Porto Alegre, 2003. 
CADERNOS DE COMUNICAÇÃO

UNIVERSIDADE FEDERAL DE SANTA MARIA

FREITAS, Sidinéia Gomes. Comunicação Interna e o Diálogo nas Organizações. In: KUNS$\mathrm{CH}$, Margarida Maria Krohling (Org). Gestão Estratégica em Comunicação Organizacional e Relações Públicas. São Caetano do Sul; SP: Difusão editora, 2009.

GIL, Antonio Carlos. Gestão de Pessoas: enfoque nos papéis profissionais. São Paulo: Atlas, 2010.

GOMES, Pedro Gilberto. Tópicos de teoria da comunicação. São Leopoldo: Unisinos, 1997.

GONÇALVES, Gisela. Introdução à Teoria das Relações Públicas. Porto: Porto Editora, 2010.

GUEDES, Éllida Neiva. Alinhamento estratégico: a comunicação interna e os objetivos organizacionais. 2007. Dissertação (Mestrado em Interfaces Sociais da Comunicação) Escola de Comunicações e Artes, Universidade de São Paulo, São Paulo. Disponível em: <http://www.teses.usp.br/teses/disponiveis/27/27154/tde-22072009-180229/>. Acesso em 02 nov. 2015.

GRUNIG, James E.; HUNT, Todd. Dirección de Relaciones Públicas. Barcelona: Gestión $2000,2003$.

HABERMAS, J. Theorie des Kommunikativen Handelns. Frankfurt: Suhrkamp Verlag, 2v., 1981.

KUNSCH, Margarida Maria Krohling. Planejamento de relações públicas na comunicação integrada. São Paulo: Summus, 2003.

. Gestão estratégica em comunicação organizacional e relações públicas. São Caetano do Sul, SP: Difusão Editora, 2009.

MARCHIORI, Marlene. Os desafios da comunicação interna nas organizações. Conexão- Comunicação e Cultura, UCS, Caxias do Sul, v. 9, n 17, jan/jun 2010a. Disponível em: <http://www.uel.br/grupo-estudo/gecorp/images/os_desafios_de_comunica_interna. pdf >. Acesso em: 20 nov. 2015.

MÓSCA, Hugo Motta B.; CEREJA, José Ricardo; BASTOS, Sérgio Augusto P. Gestão de pessoas nas organizações contemporâneas. Rio de Janeiro: LTC, 2014.

NASSAR, Paulo. Conceitos e Processos de Comunicação Organizacional. In: KUNSCH, Margarida Maria Krohling (Org.). Gestão Estratégica em Comunicação Organizacional e Relações Públicas. São Caetano do Sul, SP: Difusão editora, 2009.

SICREDI. Sobre o Sicredi. Santa Maria, 2016. Disponível em: <https://www.sicredi.com.br/ html/conheca-o-sicredi/quem-somos/>. Acesso em: 11 abr. 2016.

TORQUATO, Gaudêncio. Comunicação nas organizações: empresas privadas, instituições e setor público. São Paulo: Summus, 2015.

VIZEU, Fabio. Algumas contribuições da Teoria da Ação Comunicativa para a área de organizações. In: ENANPAD - Encontro da Associação Nacional dos Programas de Pós-Graduação em Administração, 2003, Atibaia-SP. XXVII ENANPAD. Rio de Janeiro: ANPAD, 2003. Disponível em: < http://www.anpad.org.br/diversos/trabalhos/EnANPAD/ enanpad_2003/TEO/2003_TEO106.pdf>. Acesso em: 11 abr. 2016. 


\section{Charlene Dalcol}

Relações Públicas pela Universidade Federal de Santa Maria (UFSM); Especialista em Gestão de Pessoas e Marketing pelo Centro Universitário Franciscano (UNIFRA); Mestre em Engenharia de Produção pela UFSM; Doutorando do Programa de Pós-Graduação em Comunicação da UFSM, na linha de pesquisa Mídia e Estratégias Comunicacionais; Relações Públicas da FAPAS e Professora dos cursos de pós-graduação, na área de Administração, da FAPAS.

E-mail: charlenedalcol@gmail.com

\section{Carolina Graziadei}

Jornalista pela Universidade Católica de Pelotas (UCPEL); Especialista em Gestão de Pessoas e Marketing (FAPAS); Assessora de Comunicação no Ministério do Desenvolvimento Social e Agrário em Brasília.

E-mail: carolinagraziadei@hotmail.com

\section{Fabrise Müller}

Relações Públicas pela Universidade Federal de Santa Maria (UFSM); Especialista em Marketing e Recursos Humanos (UFSM); Especialista em Gestão de Empresas pela Fundação Getúlio Vargas; Mestre em Administração e Negócios (PUCRS); Doutoranda em Comunicação Midiática (UFSM); Professora da Antonio Meneghetti Faculdade e Professora Substituta dos cursos de Comunicação Social da UFSM.

E-mail: fabrise.sma@terra.com 